\title{
QUALITY AND COST SAVING OF USING PATIENT'S OWN MEDICINES IN MULTIDISCIPLINARY WARD OF HOSPITAL SUNGAI BAKAP, PULAU PINANG, MALAYSIA
}

\author{
NURZAHAN ABDUL MAJID @ HASSAN ${ }^{*}$, KUGANESSWARI A/P SUBRAMANIAM ${ }^{2}$, \\ AMIRAH AZMAN ${ }^{3}$, KIREN SHARMA ${ }^{1}$, NOORSUHADA SHAARANI ${ }^{3}$, NOR AZRENA \\ SUHAIDA JALAUDDIN ${ }^{4}$ AND TEH SHIH CHIE ${ }^{3}$ \\ ${ }^{1}$ Unit Farmasi, Klinik Kesihatan Bandar Tasek Mutiara, Pulau Pinang, Malaysia \\ 2Jabatan Farmasi, Hospital Balik Pulau, Pulau Pinang, Malaysia \\ ${ }^{3}$ Unit Farmasi dan Bekalan, Hospital Sungai Bakap, Pulau Pinang, Malaysia \\ ${ }^{4}$ Pejabat Kesihatan Daerah Seberang Perai Selatan, Pulau Pinang, Malaysia
}

Published online: 24 May 2021

To cite this article: NURZAHAN ABDUL MAJID @ HASSAN, KUGANESSWARI A/P SUBRAMANIAM, AMIRAH AZMAN, KIREN SHARMA, NOORSUHADA SHAARANI, NOR AZRENA SUHAIDA JALAUDDIN \& TEH SHIH CHIE (2021) Quality and cost saving of using patient's own medicines in multidisciplinary ward of Hospital Sungai Bakap, Pulau Pinang, Malaysia, Malaysian Journal of Pharmaceutical Sciences, 19(1): 45-63, https://doi.org/10.21315/mjps2021.19.1.4

To link to this article: $h$ ttps://doi.org/10.21315/mjps2021.19.1.4

\begin{abstract}
Patient's Own Medicines (POMs) are medicines that were prescribed by the doctor or bought by patient and had been brought to hospital for treatment in ward. Patients were advised to bring POMs for better continuation of treatment. The objectives of this study were to assess the quality of POMs and determine the cost saving of POMs in multidisciplinary wards of Hospital Sungai Bakap (HSB). A prospective observational study was conducted from 1st January 2019 to 31st December 2019. The participation involved all patients admitted to the multidisciplinary wards that brought their own medicines during the study period. The quality of the medications was assessed by clinical pharmacists prior to be used as POMs. The criteria includes the name of medicine, strength, date of supplied, name and address of original supplier, physical appearance, colour, expiration date, batch number, date of opening for insulin and its storage. Data were collected using data collection form and were analysed using Microsoft Excel. As for the results, from the total patients that brought POMs, 136 (61\%) were from male ward and 88 (39\%) from female ward. Most of the patients that brought POMs were from middle age group, 60-69 years old (28.6\%). However, when compared to the total number of admission, patient from age group 70-79 years old has the highest percentage of patients that brought POMs (8.85\%). In terms of quality, clinical pharmacists found a total of 1,022 medications that have the quality required to be considered and were used as POMs. The total cost of savings was RM4,961.90.
\end{abstract}

"Corresponding author: nurhbm@gmail.com

(C) Penerbit Universiti Sains Malaysia, 2021. This work is licensed under the terms of the Creative Commons Attribution (CC BY) (http://creativecommons.org/licenses/by/4.0/). 
In conclusion, a standard checklist of quality criteria to assess POMs can be developed and used in each hospital settings to ensure more systematic assessment of POMs brought by patients. Awareness campaigns on POMs should be promoted to increase more awareness among patient and health care providers.

Keywords: POMs, Patient's Own Medicines, Quality, Cost saving

\section{INTRODUCTION}

Patient's Own Medicines (POMs) are medicines that are prescribed by the doctor or bought by patient and had been brought to hospital for treatment in ward. In order for an accurate medication list to be generated for medication reconciliation, the patient is advised to bring their own medication to the hospital (Grissinger 2012). Therefore, this may help the pharmacist to review their medication history for better continuation and establishment of treatment (Ministry of Health Malaysia 2018).

According to Hassali et al. (2012), Ministry of Health Malaysia has introduced a policy on POMs in 2016 in health care settings with the main reason to give guidance on POMs management during patient admission to Ministry of Health Malaysia facility and to assist pharmacists in the implementation of POMs in their hospital setting. This policy is implemented starting from admission of patient into the ward until patient is discharged from ward (Ministry of Health Malaysia 2018).

A second edition of the POMs policy has been introduced in 2018 to enhance the proficiency of this programme. This is because POMs had been discovered to help in reducing the use of prescribed medicine in the hospital. Generally, the pharmacy department will supply the prescribed medication to the patients while they are hospitalised. If the medication is not in the hospital formulary, POMs can be used for continuation of the therapy (Ministry of Health Malaysia 2018).

There are a few criteria for POMs to be used in the multidisciplinary wards of Hospital Sungai Bakap (HSB). For oral medication, the tablet must be in blister packed with a clear and readable label. The loose tablet must be in a suitable container with the intact original pack. The other medicine that can be used as POMs in the ward is insulin. Insulin must be opened less than 28 days, if not kept in the refrigerator. Damaged, unrecognised, contaminated and expired POMs will not be used in the ward. Complementary medicines such as herbal remedies or homeopathy products are not to be used as POMs (Ministry of Health Malaysia 2018).

Some of the advantages of POMs are to enhance medication adherence after discharge, establish treatment of the patient, reduce drug wastage and promote cost savings of the hospital. Besides that, the implementation of POMs will increase patient satisfaction by letting them use familiar medications and also saving time for the medical staff in drug distribution and administration for the patient in the ward (Lummis, Sketris and Veldhuyzen van Zanten 2006).

The significance of this study is to adapt the Ministry of Health Malaysia policy into our hospital setting and encourage patients to bring their own medications upon admission. The quality of POMs should be reassessed upon patient admission into the ward. Only the suitable ones will be used as POMs in the wards upon assessment of its quality.

Malay J Pharm Sci, Vol. 19, No. 1 (2021): 45-63 


\section{OBJECTIVES}

The objectives of this study were to assess the quality of POMs as well as to determine the cost saving of POMs in multidisciplinary wards of HSB.

\section{JUSTIFICATION OF THE STUDY}

Patients usually bring their own medications during admission into the ward, especially when they just received medicines a few days before admission and still have a lot of balance in their storage. Before POMs can be used in the ward, the quality of medicines must be rechecked by health care provider whether the medication is recognisable, in good condition and not expired (Grissinger 2012).

In the United Kingdom, about £90 (RM483.55) millions worth of POMs have been destroyed each year (Nielsen et al. 2013). Some of the patients bring medicines that are not acceptable to be used thus the medicines are returned back to patient or their caregiver (Grissinger 2012). Hence, it is vital that the quality of medicines brought by the patient must be assessed to provide continuity of care. POMs that were not usable commonly failed to fulfill the criteria of the original packaging, already expired, not hygienic, had unknown contents and stored inappropriately (Nielsen et al. 2013).

Besides, the implementation of POMs could lead to a reduction in the wastage of medication. Medication wastage gives a financial burden to the nation's economy and also has a negative impact on the environment due to its disposal methods. According to the Department of Health in the United Kingdom in 2009, the direct cost of unused prescription medication to the National Health Service was around to $£ 300$ (RM1,611.82) million yearly (Nurolaini, Sultana and See 2016). In North Wales, it was reported that over £1.1 (RM5.91) million worth of medicines are returned back to the pharmacist to be disposed.

A research study done in Hospital Tunku Jaafar in Seremban, Negeri Sembilan discovered that the total cost of medication wastage of hypertensive patient was RM4,362.28 with average wastage being RM42.35 per patient. The overall total cost was RM59,566.50 with the average wastage RM9,927.75 per month (Hassali et al. 2012). To reduce the cost of medication wastage, POMs programme can be initiated at all government hospitals by encouraging patient to bring their own medicine when admitted into the ward (Lummis, Sketris and Veldhuyzen van Zanten 2006).

\section{METHODS}

\section{Research Design and Population Selection}

This prospective and observational study was conducted in multidisciplinary wards which were male ward and female ward of HSB, Pulau Pinang. This study was aimed to ask patients to bring their current medication in the original containers during ward admission. This was to facilitate medication history taking and to enable the health practitioners to identify the current treatment regimen followed by the patient.

In handling with POMs in the ward, it is important to be aware that these medicines are the property of the patient and must not be destroyed or disposed without the patient's agreement. Thus, an informed consent would be obtained by the clinical pharmacist before proceeding. A copy would be given to patient. These medications are solely for this patient 
and would not be used in the treatment of any other patient. POMs may only be used where their quality had been assessed and approved by the clinical pharmacist.

Unlike medicines supplied by the pharmacy services within the hospital, there was no continuous assessment for the quality of the medicines brought in by patients. Therefore, POMs may be used only where their quality had been assessed and approved by the clinical pharmacist. If the quality was deemed satisfactory and the medicine was required for patient's treatment in ward, then POMs would be used upon discharge.

The balance medication retrieved from patient would be written on the 'balance from previous supply' column in Medication History Assessment Form (CP1). If the patient was transferred to a different ward or different facility, nurses in ward play a vital role in making sure that the medications were sent together with patient.

POMs which are stopped or withheld in ward will be tied together and put in a plastic by the clinical pharmacist and given to ward supply pharmacy. POMs which are spoiled and expired will be informed to the patient of their medication status before sending it to ward supply pharmacy for disposal. Refer Figure 1 for POMs discharged workflow.

In terms of population selection for participation, all patients that were admitted to the male ward and female ward of HSB from January to December of 2019, whom brought prescribed medicines would be included. Their participation would last until the day of their discharge.

\section{Inclusion and Exclusion Criteria}

POMs may only be considered suitable for use if the inclusion criteria is met:

\section{Inclusion criteria}

(i) Patient in male ward and female ward

(ii) Patient or caregiver sign consent form

(iii) Medicine from Ministry of Health Malaysia facility with label clear with patient's name, name and strength of medicine, date supplied, name and address of original supplier, legible expiration date

\section{Exclusion criteria}

(i) Quota or list A medications which are started by other facilities

(ii) Self-purchase medicines

(iii) Controlled drugs

(iv) Dangerous and psychotropic substance

(v) Medicines which are not available in HSB formulary

(vi) Traditional medicines

(vii) Supplements and vitamins

(viii) Patient who are minors or vulnerable subjects such as pregnant women, prisoners, cognitively impaired person, economically and/or educationally disadvantage, AIDS/HIV positive subject and terminally ill subject

\section{Sample Size}

This study was conducted for a period of 12 months from 1 January 2019 to 31 December 2019. All patients that were admitted in male ward and female ward of HSB during this period of study were included in this study. Selection of medication would be based on inclusion and exclusion criteria. Patient whom did not bring their medication on first day of ward admission would be asked to bring on the following day through their caregiver. 


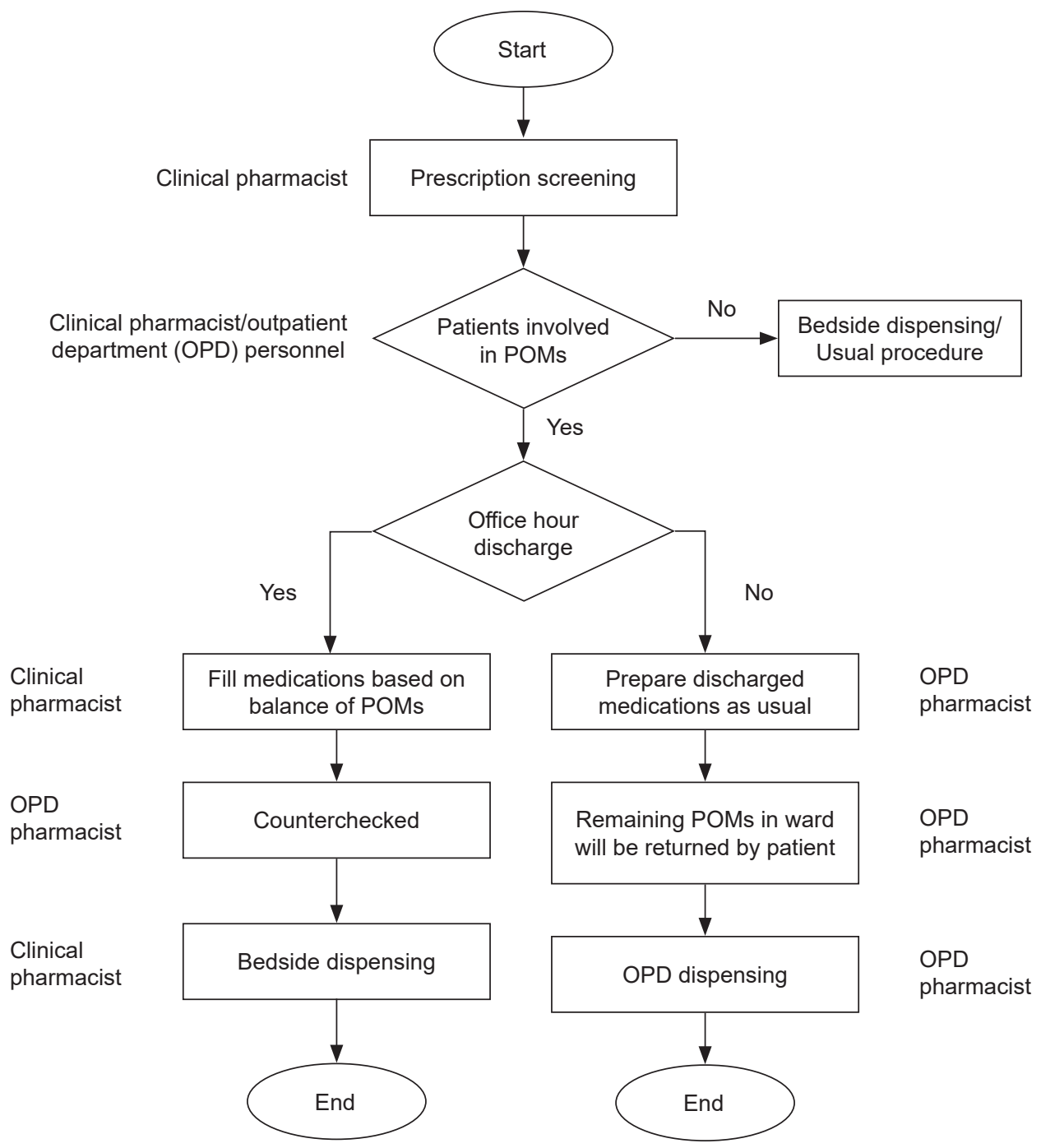

Figure 1: POMs discharged workflow.

\section{Data Collection Methods}

All data were collected using a data collection form that was created based on POMs guideline and previous research done on POMS. There will be no physical, psychological, social and economic risk involved. Every participant would be identified by using a special ID. All information obtained from this research were kept and handled confidentially, as mentioned by the related law. 


\section{Methods of Data Analysis}

All collected data were tabulated and analysed using the Microsoft Excel for Windows. The frequency and percentage of each parameter were evaluated. Descriptive statistics were used in identifying amount of accepted POMs during discharge and amount of cost savings from POMs that been used during discharge. The quality of medicines brought was assessed across type of medicines (oral, insulin and multiple daily injection) before being used for POMs. Data would be presented in a table.

\section{Expected Outcomes}

POMs shall contribute to the cost savings of expenditure in health care settings if awareness was increased among patient and health care providers. The result from this study could be used to evaluate the cost savings from POMs. This would help to save the hospital's expenditure and reduce drug wastage when patients bring their medicine upon admission into the ward. Besides that, the implementation of POMs in the hospital would provide patients with familiar use of medicine.

\section{RESULTS}

The results of this study are presented in three sequences. Firstly on distribution of patients and POMs, followed by on quality of POMs and lastly on cost savings of POMs using descriptive data analysis.

\section{Distribution of Patients and POMs}

Out of 2,047 admission of patients into male ward, 136 patients brought POMs in the ward during admission and were used as their discharge medication after POMs was assessed for quality and gave a rate of $61 \%$ from total amount patient brought POMs. Whereby, $88(39 \%)$ patients brought POMs in the female ward out of 1,508 of admission in 2019.

For gender distribution, when compared these both multidisciplinary, more patients in male ward brought POMs compared to female ward. While for age distribution, the group age of patients was categorised into eight different age groups which are patients between the age groups of 10 years old and 19 years old, 20 years old and 29 years old, 30 years old and 39 years old, 40 years old and 49 years old, 50 years old and 59 years old, 60 years old and 69 years old, 70 years old and 79 years old, and lastly 80 years old and above.

From this study, it was found out that most of the admission of patients is from the middle age groups which are $60-69$ years old, which is $21.8 \%$. This is followed by patient from age group of 50-59 years old (19.1\%) and by the age group of 70-79 years old $(14.6 \%)$. The least patient (4.3\%) was from the age groups of 10-19 years old (Table 1).

Similarly, it was found out that most of the patients brought POMs are from the middle age groups which are $60-69$ years old, which is $28.6 \%$. This is followed by patient from age group of $50-59$ years old $(23.7 \%)$ and by the age group of $70-79$ years old $(20.5 \%)$. The least patient $(0.4 \%)$ was from the age groups of $10-19$ years old (Table 1$)$.

Malay J Pharm Sci, Vol. 19, No. 1 (2021): 45-63 
Table 1: Distribution of admission $(N=3,555)$ and patient brought POMs $(N=224)$.

\begin{tabular}{|c|c|c|c|}
\hline & Male ward & Female ward & Total (\%) \\
\hline Admission $(n)$ & 2,047 & 1,508 & 3,555 \\
\hline \multicolumn{4}{|l|}{ Age group (years old) } \\
\hline 10-19 & 83 & 70 & $153(4.3)$ \\
\hline 20-29 & 200 & 127 & $327(9.2)$ \\
\hline 30-39 & 221 & 129 & $350(9.8)$ \\
\hline $40-49$ & 333 & 178 & $511(14.4)$ \\
\hline $50-59$ & 417 & 263 & $680(19.1)$ \\
\hline $60-69$ & 435 & 341 & $776(21.8)$ \\
\hline 70-79 & 251 & 269 & $520(14.6)$ \\
\hline$\geq 80$ & 107 & 131 & $238(6.7)$ \\
\hline Patients brought POMs, n (\%) & $136(61 \%)$ & $88(39 \%)$ & 224 \\
\hline Age group (years old) & & & $N(\%)$ \\
\hline 10-19 & 1 & 0 & $1(0.4)$ \\
\hline 20-29 & 6 & 3 & $9(4.0)$ \\
\hline 30-39 & 6 & 4 & $10(4.5)$ \\
\hline $40-49$ & 18 & 7 & $25(11.2)$ \\
\hline $50-59$ & 34 & 19 & $53(23.7)$ \\
\hline $60-69$ & 37 & 27 & $64(28.6)$ \\
\hline 70-79 & 26 & 20 & $46(20.5)$ \\
\hline$\geq 80$ & 8 & 8 & $16(7.1)$ \\
\hline
\end{tabular}

However, when compared percentage of admission according to age groups, with total number of patients brought POMs, we found out that the highest age group was $70-79$ years old $(8.85 \%)$. This is followed by patients from age group of $60-69$ years old $(8.25 \%)$ and by the age group of $50-59$ years old $(7.79 \%)$. The least patients $(0.65 \%)$ were from the age groups of 10-19 years old (Table 2).

From our study, we found that most patients tend to bring two types of medication upon admission (15.6\%), followed by three types (14.7\%). Approximately, 1,022 type of medicines were brought by patients from both male ward and female ward, with $59.2 \%$ and $40.7 \%$, respectively. While the mean amount of POMs brought by each patient was 4.6 for both ward (Table 3). 
Table 2: Percentage of admission versus patients brought POMs.

\begin{tabular}{lccc}
\hline Age group (years old) & Admission $(\boldsymbol{n})$ & Patients brought POMs $(\boldsymbol{n})$ & Percentage $(\%)$ \\
\hline $10-19$ & 153 & 1 & 0.65 \\
$20-29$ & 327 & 9 & 2.75 \\
$30-39$ & 350 & 10 & 2.86 \\
$40-49$ & 511 & 25 & 4.89 \\
$50-59$ & 680 & 53 & 7.79 \\
$60-69$ & 776 & 64 & 8.25 \\
$70-79$ & 520 & 46 & 8.85 \\
$\geq 80$ & 238 & 16 & 6.72 \\
\hline Total & 3,555 & 224 & 42.76 \\
\hline
\end{tabular}

Table 3: Quantity POMs brought by patient $(N=1,022)$.

\begin{tabular}{lccc}
\hline & Male ward & Female ward & Total (\%) \\
\hline Quantity POMs brought by patient, $n(\%)$ & & & \\
1 & 18 & 11 & $29(12.9)$ \\
2 & 25 & 10 & $35(15.6)$ \\
3 & 16 & 17 & $33(14.7)$ \\
4 & 18 & 8 & $26(11.6)$ \\
5 & 12 & 9 & $21(9.4)$ \\
6 & 12 & 11 & $23(10.3)$ \\
7 & 11 & 5 & $16(7.1)$ \\
8 & 12 & 6 & $18(8.0)$ \\
9 & 9 & 6 & $15(6.7)$ \\
10 & 1 & 2 & $3(1.3)$ \\
11 & 2 & 2 & $4(1.8)$ \\
12 & 0 & 1 & $1(1.1)$ \\
\hline POMs, $n(\%)$ & $606(59.2 \%)$ & $416(40.7 \%)$ & 1,022 \\
\hline Mean quantity of POMs per patient & 4.5 & 4.7 & 4.6 \\
\hline
\end{tabular}

\section{Quality of POMs}

Each medication brought by the patient has been assessed by the clinical pharmacist in each ward before they were used as part of their discharge medication. The criteria includes the name of medicine, strength, date of supplied, name and address of original supplier, physical appearance, colour, expiration date, batch number, date of opening for insulin and its storage. POMs that were expired, stored inappropriately, had unidentifiable contents, split, stored in containers different from original packaging, and without a proper label, will be excluded. 
According to our study conducted in HSB for a period of one year in 2019, out of 3,555 patients, only 224 patients $(6.3 \%)$ brought their medications for use during admission. The total number of POMs that were used in that period is 1,022 . This shows that the clinical pharmacist found a total of 1,022 medications to have the quality required to be considered for use as POMs.

\section{Cost Savings}

About 12 types of pharmacological groups were categorised from POMs brought by patients. Majority of the POMs brought by patients were from pharmacological groups of cardiovascular (37.9\%). These were followed by endocrine group $(12.6 \%)$ and respiratory group $(11.7 \%)$. Table 4 shows the type of medicine brought according to each pharmacological group.

Table 4: Type of medicine brought according to pharmacological group.

\begin{tabular}{llcc}
\hline No & Pharmacological group & Type of medicine brought & Percentage (\%) \\
\hline 1 & Gastro-intestinal & 4 & 3.9 \\
2 & Cardiovascular & 39 & 37.9 \\
3 & Respiratory & 12 & 11.7 \\
4 & Analgesic & 3 & 2.9 \\
5 & Psychiatry & 4 & 3.9 \\
6 & Neurology & 11 & 10.7 \\
7 & Anti-infectives & 1 & 1.0 \\
8 & Endocrine & 13 & 12.6 \\
9 & Genitourinary & 3 & 2.9 \\
10 & Nutrition and blood disorders & 10 & 9.7 \\
11 & Rheumatology & 1 & 1.0 \\
12 & Ear, nose and oropharyx & 2 & 1.9 \\
\hline & & 103 & 100 \\
\hline
\end{tabular}

Table 5 shows the name of medicine that has been brought by patient and its amount. The highest POMs brought by patient were calcium carbonate $500 \mathrm{mg}$ tablet (2,456 tablets), followed by metformin $500 \mathrm{mg}$ tablet (1,842 tablets) and frusemide $40 \mathrm{mg}$ tablet (1,337 tablets). Other than medicine in tablet dosage form, patient also brought insulin penfill and inhalers during admission into the wards. 
Table 5: Name of medicine according to pharmacological group.

\begin{tabular}{|c|c|c|c|}
\hline No. & $\begin{array}{l}\text { Pharmacological } \\
\text { group }\end{array}$ & Name of medicine & $\begin{array}{c}\text { Amount of } \\
\text { accepted POMs }\end{array}$ \\
\hline 1 & Gastrointestinal & Bisacodyl $5 \mathrm{mg}$ tablet & 40 \\
\hline 2 & & Domperidone $10 \mathrm{mg}$ tablet & 120 \\
\hline 3 & & Pantoprazole $40 \mathrm{mg}$ tablet & 817 \\
\hline 4 & & Ranitidine $150 \mathrm{mg}$ tablet & 453 \\
\hline 1 & Cardiovascular & Acetylsalicylic acid $100 \mathrm{mg} / \mathrm{glycine} 45 \mathrm{mg}$ tablet & 999 \\
\hline 2 & & Amlodipine $5 \mathrm{mg}$ tablet & 14 \\
\hline 3 & & Amlodipine $10 \mathrm{mg}$ tablet & 832 \\
\hline 4 & & Amlodipine $10 \mathrm{mg} / \mathrm{valsartan} 160 \mathrm{mg}$ tablet & 30 \\
\hline 5 & & Atenolol $100 \mathrm{mg}$ tablet & 7 \\
\hline 6 & & Atorvastatin $40 \mathrm{mg}$ tablet & 60 \\
\hline 7 & & Atorvastatin $80 \mathrm{mg}$ tablet & 391 \\
\hline 8 & & Bisoprolol $2.5 \mathrm{mg}$ tablet & 164 \\
\hline 9 & & Bisoprolol $5 \mathrm{mg}$ tablet & 345 \\
\hline 10 & & Captopril $25 \mathrm{mg}$ tablet & 44 \\
\hline 11 & & Carvedilol $6.25 \mathrm{mg}$ tablet & 10 \\
\hline 12 & & Carvedilol $25 \mathrm{mg}$ tablet & 213 \\
\hline 13 & & Clopidogrel $75 \mathrm{mg}$ tablet & 272 \\
\hline 14 & & Diltiazem $30 \mathrm{mg}$ tablet & 296 \\
\hline 15 & & Enalapril $10 \mathrm{mg}$ tablet & 10 \\
\hline 16 & & Felodipine $10 \mathrm{mg}$ tablet & 743 \\
\hline 17 & & Fenofibrate $145 \mathrm{mg}$ tablet & 30 \\
\hline 18 & & Frusemide $40 \mathrm{mg}$ tablet & 1,337 \\
\hline 19 & & Gemfibrozil $300 \mathrm{mg}$ tablet & 214 \\
\hline 20 & & Glyceryl trinitrate $0.5 \mathrm{mcg}$ sublingual tablet & 688 \\
\hline 21 & & Hydroclorothiazide $25 \mathrm{mg}$ tablet & 51 \\
\hline 22 & & Isosorbide mononitrate $60 \mathrm{mg}$ tablet & 38 \\
\hline 23 & & Isosorbide dinitrate $30 \mathrm{mg}$ tablet & 546 \\
\hline 24 & & Losartan $50 \mathrm{mg}$ tablet & 38 \\
\hline 25 & & Losartan $100 \mathrm{mg}$ tablet & 84 \\
\hline 26 & & Metoprolol $100 \mathrm{mg}$ tablet & 240 \\
\hline 27 & & Perindopril $4 \mathrm{mg}$ tablet & 743 \\
\hline 28 & & Prazosin $1 \mathrm{mg}$ tablet & 163 \\
\hline 29 & & Prazosin $2 \mathrm{mg}$ tablet & 28 \\
\hline
\end{tabular}


Table 5: (continued)

\begin{tabular}{|c|c|c|c|}
\hline No. & $\begin{array}{l}\text { Pharmacological } \\
\text { group }\end{array}$ & Name of medicine & $\begin{array}{c}\text { Amount of } \\
\text { accepted POMs }\end{array}$ \\
\hline 30 & & Propranolol $40 \mathrm{mg}$ tablet & 43 \\
\hline 31 & & Simvastatin $10 \mathrm{mg}$ tablet & 168 \\
\hline 32 & & Simvastatin $40 \mathrm{mg}$ tablet & 1,330 \\
\hline 33 & & Spirinolactone $25 \mathrm{mg}$ tablet & 47 \\
\hline 34 & & Telmisartan $40 \mathrm{mg}$ tablet & 20 \\
\hline 35 & & Ticlopidine $250 \mathrm{mg}$ tablet & 85 \\
\hline 36 & & Trimetazidine $20 \mathrm{mg}$ tablet & 991 \\
\hline 37 & & Warfarin $1 \mathrm{mg}$ tablet & 26 \\
\hline 38 & & Warfarin $2 \mathrm{mg}$ tablet & 8 \\
\hline 39 & & Warfarin $5 \mathrm{mg}$ tablet & 42 \\
\hline 1 & Respiratory & Budesonide $200 \mathrm{mcg} /$ dose inhalation & 6 \\
\hline 2 & & $\begin{array}{l}\text { Budesonide } 160 \mathrm{mcg} \text { and formoterol } \\
4.5 \mathrm{mcg} \text { inhalation }\end{array}$ & 2 \\
\hline 3 & & Fluticasone propionate $125 \mathrm{mcg} / \mathrm{dose}$ inhaler & 1 \\
\hline 4 & & $\begin{array}{l}\text { Indacaterol } 110 \mathrm{mcg} \text { and glycopyrronium } \\
50 \mathrm{mcg} \text { inhalation capsule }\end{array}$ & 30 \\
\hline 5 & & $\begin{array}{l}\text { Ipratropium bromide } 20 \mathrm{mcg} \text { and salbutamol } \\
\text { base } 100 \mathrm{mcg} / \mathrm{dose} \text { inhalation }\end{array}$ & 6 \\
\hline 6 & & Montelukast $10 \mathrm{mg}$ tablet & 40 \\
\hline 7 & & Olodaterol $2.5 \mathrm{mcg}$ inhalation & 1 \\
\hline 8 & & Salbutamol $200 \mathrm{mcg} /$ dose inhaler & 11 \\
\hline 9 & & $\begin{array}{l}\text { Salmeterol } 50 \mathrm{mcg} \text { and fluticasone propionate } \\
250 \mathrm{mcg} \text { inhalation }\end{array}$ & 1 \\
\hline 10 & & $\begin{array}{l}\text { Salmeterol } 50 \mathrm{mcg} \text { and fluticasone propionate } \\
500 \mathrm{mcg} \text { inhalation }\end{array}$ & 1 \\
\hline 11 & & Theophylline SR $250 \mathrm{mg}$ tablet & 54 \\
\hline 12 & & Tiotropium $2.5 \mathrm{mcg} /$ puff solution inhalation & 3 \\
\hline 1 & Analgesic & Acetylsalicylic acid $300 \mathrm{mg}$ soluble tablet & 316 \\
\hline 2 & & Paracetamol $500 \mathrm{mg}$ tablet & 86 \\
\hline 3 & & Tramadol $50 \mathrm{mg}$ tablet & 245 \\
\hline 1 & Psychiatry & Olanzapine $5 \mathrm{mg}$ tablet & 7 \\
\hline 2 & & Olanzapine $10 \mathrm{mg}$ tablet & 67 \\
\hline 3 & & Quetiapine $200 \mathrm{mg}$ tablet & 80 \\
\hline 4 & & Sertraline $\mathrm{HCl} 50 \mathrm{mg}$ tablet & 14 \\
\hline
\end{tabular}


Table 5: (continued)

\begin{tabular}{|c|c|c|c|}
\hline No. & $\begin{array}{l}\text { Pharmacological } \\
\text { group }\end{array}$ & Name of medicine & $\begin{array}{c}\text { Amount of } \\
\text { accepted POMs }\end{array}$ \\
\hline 1 & Neurology & Benzhexol $2 \mathrm{mg}$ tablet & 158 \\
\hline 2 & & Carbamazepine $200 \mathrm{mg}$ tablet & 30 \\
\hline 3 & & Flunarizine $5 \mathrm{mg}$ tablet & 20 \\
\hline 4 & & Gabapentin $300 \mathrm{mg}$ tablet & 24 \\
\hline 5 & & Lamotrigine $100 \mathrm{mg}$ tablet & 112 \\
\hline 6 & & Levetiracetam $500 \mathrm{mg}$ tablet & 48 \\
\hline 7 & & Levodopa $100 \mathrm{mg}$ and carbidopa $25 \mathrm{mg}$ tablet & 98 \\
\hline 8 & & Mecobalamin 500 mcg tablet & 78 \\
\hline 9 & & Phenytoin $100 \mathrm{mg}$ capsule & 172 \\
\hline 10 & & Phenytoin $30 \mathrm{mg}$ capsule & 86 \\
\hline 11 & & Sodium valproate $200 \mathrm{mg}$ tablet & 841 \\
\hline 1 & Anti-infectives & Azithromycin $250 \mathrm{mg}$ tablet & 20 \\
\hline 1 & Endocrine & Prednisolone $5 \mathrm{mg}$ tablet & 10 \\
\hline 2 & & Carbimazole $5 \mathrm{mg}$ tablet & 29 \\
\hline 3 & & Gliclazide $80 \mathrm{mg}$ tablet & 307 \\
\hline 4 & & Gliclazide MR $30 \mathrm{mg}$ tablet & 919 \\
\hline 5 & & Hydrocortisone $10 \mathrm{mg}$ tablet & 12 \\
\hline 6 & & Levothyroxine $25 \mathrm{mcg}$ tablet & 50 \\
\hline 7 & & Levothyroxine $100 \mathrm{mcg}$ tablet & 125 \\
\hline 8 & & Metformin $500 \mathrm{mg}$ tablet & 1,842 \\
\hline 9 & & $\begin{array}{l}\text { Insulin recombinant neutral human short-acting } \\
100 \mathrm{IU} / \mathrm{mL} \text { penfill and refill (S/C actrapid) }\end{array}$ & 23 \\
\hline 10 & & $\begin{array}{l}\text { Insulin recombinant neutral human Short-acting } \\
100 \mathrm{IU} / \mathrm{mL} \text { penfill and refill (S/C insugen R) }\end{array}$ & 16 \\
\hline 11 & & $\begin{array}{l}\text { Insulin recombinant synthetic human, } \\
\text { intermediate-acting } 100 \mathrm{IU} / \mathrm{mL} \text { penfill and refill } \\
\text { (S/C insulatard) }\end{array}$ & 10 \\
\hline 12 & & $\begin{array}{l}\text { Insulin recombinant synthetic human, premixed } \\
100 \mathrm{IU} / \mathrm{mL} \text { penfill and refill (S/C insugen 30/70 ) }\end{array}$ & 13 \\
\hline 13 & & $\begin{array}{l}\text { Insulin recombinant synthetic human, premixed } \\
100 \mathrm{IU} / \mathrm{mL} \text { penfill and refill (S/C mixtard ) }\end{array}$ & 11 \\
\hline 1 & Genitourinary & Finasteride $5 \mathrm{mg}$ tablet & 18 \\
\hline 2 & & Terazosin $2 \mathrm{mg}$ tablet & 5 \\
\hline 3 & & Terazosin $5 \mathrm{mg}$ tablet & 79 \\
\hline
\end{tabular}


Table 5: (continued)

\begin{tabular}{lllc}
\hline No. & $\begin{array}{l}\text { Pharmacological } \\
\text { group }\end{array}$ & Name of medicine & $\begin{array}{c}\text { Amount of } \\
\text { accepted POMs }\end{array}$ \\
\hline 1 & $\begin{array}{l}\text { Nutrition and } \\
\text { blood disorders }\end{array}$ & Alfacalcidol 1 mcg capsule & 16 \\
2 & Ascorbic acid 100 mg tablet & 61 \\
3 & Calcium carbonate $500 \mathrm{mg}$ tablet & 2,456 \\
4 & Calcitriol 0.25 mcg capsule & 246 \\
5 & Ferrous fumarate 200 mg tablet & 1,121 \\
6 & Folic acid 5 mg tablet & 765 \\
7 & Vitamin B1, B6, B12 tablet & 378 \\
8 & Pyridoxine 10 mg tablet & 64 \\
9 & Potassium chloride SR 600 mg tablet & 98 \\
10 & & Vitamin B complex tablet & 722 \\
\hline 1 & Rheumatology & Allopurinol 300 mg tablet & 39 \\
\hline 1 & Ear, nose and & Betahistine 24 mg tablet & 16 \\
2 & oropharynx & Bromhexine 8 mg tablet & 30 \\
\hline & & Total amount of accepted POMs & 24,959 \\
\hline
\end{tabular}

From our study, we found that the highest cost savings were from cardiovascular group which is RM1,426.86 and this is followed by respiratory group (RM892.63) and finally by endocrine group (RM690.43) (Table 6). The total cost savings was RM4,961.90.

Table 6: Cost savings according to pharmacological groups.

\begin{tabular}{llc}
\hline No & Pharmacological group & Cost savings (RM) \\
\hline 1 & Gastro-intestinal & 309.73 \\
2 & Cardiovascular & $1,426.86$ \\
3 & Respiratory & 892.63 \\
4 & Analgesic & 86.07 \\
5 & Psychiatry & 582.33 \\
6 & Neurology & 402.77 \\
7 & Anti-infectives & 12.00 \\
8 & Endocrine & 690.43 \\
9 & Genitourinary & 27.17 \\
10 & Nutrition and blood disorders & 522.69 \\
11 & Rheumatology & 5.46 \\
12 & Ear, nose and oropharynx & 3.76 \\
\hline & Total cost savings & $4,961.90$ \\
\hline
\end{tabular}




\section{DISCUSSION}

\section{Distribution of Patients and POMs}

This study was conducted to assess the quality of POMs and to determine its cost savings in HSB. POMs are implemented on both wards which include male ward and female ward which are the highest admission ward in HSB. Based on the study by Wong (2014), the implementation of POMs in the hospital setting gives an advantage to medication cost budget. Medications brought by the patients with good quality are reused during discharge.

Based on this study, majority of patients who brought POMs are from male ward $(61 \%)$ compared to female ward $(39 \%)$ due to higher admission in male ward.

This study showed that patients of age group 60 years old to 69 years old have the highest percentage of brought POMs during ward admission (28.6\%), while for patients of age group $50-59$ years old and $70-79$ years old, showed percentage of $23.7 \%$ and $20.5 \%$, respectively. This is comparable to a study by Norstrom and Brown (2002), which stated that older patients prefer to take along their own medications to the hospital. According to study by Nielsen et al. (2013), most of the POMs commonly taken are oral medication that associated to ATC groups which consist of A (alimentary tract and metabolism such as vitamin and calcium supplements), $\mathrm{N}$ (nervous system) and $\mathrm{R}$ (respiratory system). However, a research study from Grissinger (2012) stated that over $12.6 \%$ patients preferred taking medication on their own because they are not pleased with services given by healthcare providers.

It is more practical for clinical pharmacist from HSB to do POMs only upon discharge due to geographical factor, time consumption, increased workload and patient factor. As for geographical factor, the location of hospital which is surrounded by hills makes it difficult for clinical pharmacist to shuttle from ward supply to multidisciplinary ward to participate in POMs programme. Thus, POMS were implemented only upon patients discharge from wards. Besides that, since the location of ward supply and wards are far from each other, it will take a longer time for ward staff to bring medication trolley from ward to ward supply. If POMs were implemented throughout admission, it definitely would increase overall workload due to more intensive procedure from admission of patient into the ward until patient was discharged (Ministry of Health Malaysia 2018).

Another reason was, most of the patient brought their medication to the hospital only after a few days of admission. This made some difficulty for the clinical pharmacist to start POMs upon admission. A study by Boachie-Ansah, Anto and Marfo (2019) discovered that most of the patient did not know that they need to bring their medicines to the hospital. Most of presented POMS are brought by relatives upon inquiry. This finding is similar with our study, that most of the patients or caregiver of multidisciplinary ward were not aware that they should bring POMs upon admission.

When POMS are implemented upon patient discharge, clinical pharmacist can review the medication and establish their treatment. Therefore, POMS can be appropriately identified and safer for use (Nielsen et al. 2013).

\section{Quality}

Medication that was included in this research as POMs were those from Ministry of Health Malaysia facility with labels that clearly stated the patient's name, name and strength of medicine, date supplied, and name and address of original supplier. We also ensured that medications used were not expired. The criteria by which we assessed the quality of the medications suitable for use as POMs were similar to various other research articles.

Malay J Pharm Sci, Vol. 19, No. 1 (2021): 45-63 
A research conducted in Ghana by Boachie-Ansah, Anto and Marfo (2019) assessed the quality of POMs according to a checklist that incorporated the credibility of the label, storage container of the medication, the expiry date, product integrity and storage of the medication. Another article published in 2013 by Nielsen et al. identified the quality of POMs according to appearance, container, label, identification, storage temperature conditions and expiration. Similarly, the national guideline of Victoria, Australia in 2007 states that medication for use in POMs should be in original packs or strip packs and should have a legible expiry date. POMs will be used when the medication is not related to the patient's chief complaint on admission, and the medication is chronically being used by the patient and is not to be discontinued.

Taking these articles as a guide, we ensured the medication used as POMs for this research were stored properly and had an appropriate label complete with the name of medication with a viable expiry date.

The South Australian government published a policy regarding the implementation of POMs in 2018. This policy states that appropriate assessment which ensures the safety and quality of POMs is vital before use. Local health organisations make the decision in allowing the use of POMs during admission. The administration of POMs to patients will only be done if the treating health care practitioner prescribes it for inpatient use. The suitability of POMs is assessed before use. Thus, it was crucial that the medication included in this research as POMs be indicated for use upon patient admission. Medications that were not indicated were excluded from this research.

A policy on POMs published in 2014 by the Tasmanian government encourage that POMs are managed by the Tasmanian Health Organisation staff during admission, are stored appropriately and are returned to the patient upon discharge. It also states the conditions that are suitable for POMs to be used. Likewise, we stored the patients medication used as POMs separately and ensured that the medications used as POMs were returned to the patient upon discharge.

It is apparent that medications of suitable quality as stated above are credible for use as POMs. However, medications that fail to have a legible expiration date or that are kept in personal dose boxes without any label fail to meet the inclusion criteria and hence are not used in this study. With no expiration or re-dispensing date, the chemical and physical integrity of the drug cannot be validated in the hospital. This, thus, raises a question regarding the safety and efficacy of the drug which renders it unsuitable for inpatient use.

\section{Cost Savings}

Cost saving was indeed a crucial factor in implementing POMs. The budget of medications used in the hospital may have substantial reduction when all or most of the POMs are used. Throughout the 12 months study in HSB, a total cost of RM4,961.90 was saved from the POMs collected. This figure reflects that, out of the 224 patients who brought POMs during admission, there was a saving of RM22.15 per patient. The results were comparable to the study carried out by Mc Robbie, Bednall and West (2003), as the cost saved was almost the salary of a clinical pharmacist's to provide service to the medical ward.

The pharmacological group of POMs collected were being categorised into 12 types as stated in Table 4. Among the varieties of POMs brought by patients admitted in HSB, majority types of POMs are from the pharmacological groups of cardiovascular $(37.9 \%)$, endocrine $(12.6 \%)$ and followed by respiratory $(11.7 \%)$. This is similar to the order of pharmacological groups that contributed the most in cost savings. The cardiovascular group contributed a total of RM1,426.86 (28.7\%), followed by the respiratory group and 
endocrine group which contributed a total of RM892.63 (18.0\%) and RM690.43 (13.9\%), respectively.

POMs of cardiovascular groups contributed the most as this might be due to the fact that cardiovascular diseases are the number one cause of death globally (World Health Organization, 2017). According to Müller (2019), disease of respiratory systems (13.86\%) and disease of the circulatory system $(8.01 \%)$ are in the top five causes of hospitalisation in Malaysia. This may certainly explain the high contribution of POMs from cardiovascular groups and respiratory groups.

On the other hand, the least contribution of POMs is from the anti-infective group $(1.0 \%)$, rheumatology group $(1.0 \%)$, and ear, nose and oropharynx group $(1.9 \%)$. Therefore, the least cost savings were obtained from these groups. The anti-infective group generated RM12.00 (0.24\%), the rheumatology group RM5.46 $(0.11 \%)$, as well as ear, nose and oropharynx group RM3.76 $(0.08 \%)$. The anti-infective group as the least type of medication brought, showed a good sign which reflects that most of the patients admitted to HSB were in compliance towards the short term courses of anti-infective medications, and thus no unnecessary balance of medication from that group was being kept with patients during admission. Rheumatology group and ear, nose and oropharynx group are in the three least types of POMs, this might be due to low rates of hospitalisation (Müller 2019) and hence the low admission rate in HSB due to these diseases.

The total amount of medication being collected throughout the period of this study was 24,959 tablets. The highest amount of medication being brought by patients was calcium carbonate $500 \mathrm{mg}$ tablet $(2,456$ tablets, $9.84 \%)$. It was followed by metformin $500 \mathrm{mg}$ tablet (1,482 tablets, $5.94 \%)$ and frusemide $40 \mathrm{mg}$ tablet (1,337 tablets, 5.36\%). Such an amount of POMs collected were all reissued as home medication upon discharge and hence directly reduced the amount and cost of medication. As well, this also removed unsuitable or unneeded POMs so patients do not return home and continue to use them (Jacklin, Patel and Almossawi 2001). Bennett (1994) found that POMs could help to clarify confused patients on the altered medication regime during admission.

Whereas, when viewing the total amount of POMs collected according to the pharmacological group, cardiovascular group was significantly showing the highest amount of tablets being collected which consists of 11,390 tablets/capsules (45.6\%). This ranking was tally with the cost of POMs as cardiovascular medications contribute the most as well. Pharmacological group of nutrition and blood disorder was rank as the second highest amount of POMs being collected, which is 5,927 tablets/capsules (29.7\%). The third most was falling under the pharmacology group of endocrine, 3,387 tablets/capsules $(13.5 \%)$.

Within the pharmacological group of cardiovascular, frusemide $40 \mathrm{mg}$ tablets (1,337 tablets, $5.36 \%)$, simvastatin $40 \mathrm{mg}$ tablet (1,330 tablets, $5.33 \%)$ and acetylsalicylic acid $100 \mathrm{mg} / \mathrm{glycerin} 45 \mathrm{mg}$ tablet (999 tablets, 4.00\%) are the three most collected POMs. The least collected POMs of the pharmacological group of cardiovascular is warfarin $2 \mathrm{mg}$ tablet (eight tablets, 0.03\%).

Within the pharmacological group of nutrition and blood disorder, carbonate $500 \mathrm{mg}$ tablet $(2,456$ tablets, $9.84 \%)$, ferrous fumarate $200 \mathrm{mg}$ tablet $(1,121$ tablets, $4.49 \%$ ), folic acid $5 \mathrm{mg}$ tablet (765 tablets, $3.07 \%)$ are the three most collected POMs. The least collected POMs of the pharmacological group of nutrition and blood disorder is alfacalcidol $1 \mathrm{mcg}$ capsule (16 tablets, $0.06 \%$ ).

Within the pharmacological group of endocrine, metformin $500 \mathrm{mg}$ tablet $(1,842$ tablets, $7.38 \%$ ), gliclazide MR $30 \mathrm{mg}$ tablet (919 tablets, $3.68 \%)$ and gliclazide $80 \mathrm{mg}$ tablet (307 tablets, $1.23 \%)$ are the three most collected POMs. The least collected POMs of the pharmacological group of endocrine is the insulin recombinant synthetic human, intermediate-acting $100 \mathrm{IU} / \mathrm{mL}$ penfill and refill (S/C insulatard) (10 cartridges, $0.04 \%$ ).

Malay J Pharm Sci, Vol. 19, No. 1 (2021): 45-63 
Through the collected POMs, pharmacology group of ear, nose and oropharynx (46 tablets, $0.18 \%$ ), rheumatology (39 tablets, $0.16 \%$ ) and anti-infective group (20 tablets, $0.08 \%$ ) are the three most least collected POMs. Ear, nose and oropharynx group consist of two medications which are bromhexine $8 \mathrm{mg}$ tablet (30 tablets, $0.12 \%$ ) and betahistine $24 \mathrm{mg}$ tablet (16 tablets, $0.06 \%$ ). Rheumatology group consist of only allopurinol $300 \mathrm{mg}$ tablet (39 tablets, $0.16 \%$ ). Anti-infective group consists of only azithromycin $250 \mathrm{mg}$ tablet (20 tablets, $0.08 \%$ ). The lesser the anti-infective group POMs being collected, the better it is, which reflects that most of the patients admitted to HSB were taking serious acting in adhering the antibiotic therapy being prescribed. This will further reduce the outcomes of antibiotic resistance in the community and residential area surrounding HSB.

\section{LIMITATIONS}

There are a few limitations in implementation of POMs in the ward of HSB, thus the cost savings from this study cannot be used to describe the whole cost savings from the whole admission in HSB. This mainly because this study only included two main wards out of the five wards in HSB.

Besides that, no awareness campaign on POMs was done before this study took place. Many of the patients were not aware of this programme and did not know that they should bring their medicine upon admission. Many of the patients did not bring their previous medicine throughout the admission as their caregivers were quite busy with their work schedule. For those who did not bring, medication history was traced through Pharmacy Information System (PhIS).

Language barrier between patient and clinical pharmacist also plays an important role as they cannot interact well with patient when there was no caregiver around for assistance. The limitation list here might affect the findings of this study as well.

\section{CONCLUSION}

In this study, it can be concluded that quality of POMs should be assessed in detail before patient medications are used as part of their discharge medication. A checklist of quality criteria to assess POMs can be developed and can be used in hospital setting to ensure more systematic assessment of POMs brought by patient. Amount of accepted POMs per patient rely on the quality assessment by clinical pharmacist.

In term of cost savings, a total cost of RM4,961.90 was saved after POMs was implemented in two multidisciplinary wards with zero awareness campaign of POMs done in HSB. Awareness campaigns on POMs are important to increase awareness not only among patient but also among health care providers. Health care providers such as doctors and nurses are the first front liners to see patients in the ward besides clinical pharmacist.

If both health care providers and campaigns play important roles, a higher total cost of POMs implementation can be saved. Besides, patient's compliance on medication can be assessed through POMs.

This study is merely on cost description. Researchers are suggested to do future studies comparing cost saving with intervention and cost saving without intervention. 


\section{ACKNOWLEDGEMENTS}

We would like to thank the Director of HSB, Dr. Suriani Saaidin for giving us a permission to conduct this study in HSB.

\section{REFERENCES}

BENNETT, L. (1994) What happens to patients' own drugs? Hospital Pharmacy Practice, 4: 197-197.

BOACHIE-ANSAH P., ANTO B. \& MARFO A. (2019) Reuse of patients' own drugs in hospitals in Ghana: The evidence to support policy, BMC Health Services Research,19(1): 27. https://doi.org/10.1186/s12913-018-3860-9

GOVERNMENT OF SOUTH AUSTRALIA (2018) Patients' own medications policy directive. Version 1.1. (Australia: South Australian Health). https://www.sahealth. sa.gov.au/wps/wcm/connect/public+content/sa+health+internet/resources/policies/ patients+own+medications+policy+directive

GRISSINGER, M. (2012) Patients taking their own medications while in the hospital, Pennsylvania Patient Safety Advisory, 9(2): 50-57.

HASSALI, M. A., SUPIAN, A., IBRAHIM, M. I., AL-QAZAZ, H. K., AL-HADDAD, M., SALEEM, F., et al. (2012) The characteristics of drug wastage at the Hospital Tuanku Jaafar Seremban, Malaysia: A descriptive study, Journal of Clinical \& Diagnostic Research, 6(5): 787-790.

JACKLIN, A., PATEL, K. \& ALMOSSAWI, O. (2001) A discharge pharmacist service improves the timeliness, quality and cost of discharge, Pharmacy Practice, 11: 100-102.

LUMMIS, H., SKETRIS, I. \& VELDHUYZEN VAN ZANTEN, S. (2006) Systematic review of the use of patients' own medications in acute care institutions, Journal of Clinical Pharmacy and Therapeutics, 31(6): 541-563. https://doi.org/10.1111/j.1365-2710.2006.00773.x

MC ROBBIE, D., BEDNALL, R. \& WEST, T. (2003) Assessing the impact of re-engineering of pharmacy services to general medical wards, The Pharmaceutical Journal, 270: 342-345.

MINISTRY OF HEALTH MALAYSIA (2018) Policy and guideline for patients' own medicines (POMs) program. $2^{\text {nd }}$ edition. (Pharmaceutical Services Programme, Ministry of Health Malaysia). https://www.pharmacy.gov.my/v2/en/documents/policy-and-guideline-patientsown-medicines-poms-program-2nd-edition.html

MÜLLER, J. (2019) Major causes of hospitalization in Malaysia 2018. Statista. https://www. statista.com/statistics/866189/major-causes-hospitalization- malaysia/\#statisticContainer

NIELSEN, T. R. H., KRUSE, M. G., ANDERSEN, S. E., RASMUSSEN, M. \& HONORÉ, P. H. (2013) The quality and quantity of patients' own drugs brought to hospital during admission, European Journal of Hospital Pharmacy: Science and Practice, 20(5): 297-301. https://doi.org/10.1136/ejhpharm-2013-000277

Malay J Pharm Sci, Vol. 19, No. 1 (2021): 45-63 
NORSTROM, P. E. \& BROWN, C. M. (2002) Use of patients' own medications in small hospitals, American Journal of Health-System Pharmacy, 59(4): 349-354. https://doi.org/ 10.1093/ajhp/59.4.349

NUROLAINI, K., SULTANA, S. M. \& SEE, W. W. (2016) Medication wastage and its disposal amongst patients at Suri Seri Begawan Hospital in Brunei Darussalam, Medicine and Health, 11(2): 139-150. https://doi.org/10.17576/MH.2016.1102.04

POPE, L. (2007) National guidelines - patient's use of own medications. Victoria State Government. https://www2.health.vic.gov.au/about/news-and-events/hospitalcirculars/ circ1407

TASMANIAN GOVERNMENT (2014) Patients' own medications policy. http://www.catag .org.au/wp-content/uploads/2014/06/SPP-MSR-Policy-Patients-Own-Medication -20140705.pdf

WONG, G. Y. (2014) Cost impact of using patients' own multidose medications in hospital, The Canadian Journal of Hospital Pharmacy, 67(1): 9. https://doi.org/10.4212/cjhp.v67i1 .1316

WORLD HEALTH ORGANIZATION (2017) Cardiovascular disease. https://www.who.int/ health-topics/cardiovascular-diseases/ 